\title{
Knowledge outcome of visual-simulation-based over print-based diabetic retinopathy health education amongst the Omani community residing in Al Batinah, Oman
}

\begin{tabular}{|c|c|}
\hline \multicolumn{2}{|c|}{$\begin{array}{l}\text { Authors: } \\
\text { Gopi S. Vankudre } \\
\text { Sheikha M.R.D. Al Saad }\end{array}$} \\
\hline \multicolumn{2}{|c|}{$\begin{array}{l}\text { Affiliations: } \\
{ }^{1} \text { Department of Optometry, } \\
\text { College of Health Sciences, } \\
\text { University of Buraimi, } \\
\text { Al Buraimi, Oman }\end{array}$} \\
\hline \multicolumn{2}{|c|}{$\begin{array}{l}\text { Corresponding author: } \\
\text { Gopi Vankudre, } \\
\text { gopi_vankudre@yahoo.co.in }\end{array}$} \\
\hline \multicolumn{2}{|c|}{$\begin{array}{l}\text { Dates: } \\
\text { Received: } 22 \text { May } 2020 \\
\text { Accepted: } 09 \text { Dec. } 2020 \\
\text { Published: } 28 \text { Apr. } 2021\end{array}$} \\
\hline \multicolumn{2}{|c|}{$\begin{array}{l}\text { How to cite this article: } \\
\text { Vankudre GS, Al Saad SMRD, } \\
\text { Knowledge outcome of } \\
\text { visual-simulation-based over } \\
\text { print-based diabetic } \\
\text { retinopathy health education } \\
\text { amongst the Omani } \\
\text { community residing in Al } \\
\text { Batinah, Oman. Afr Vision Eye } \\
\text { Health. 2021;80(1), a581. } \\
\text { https://doi.org/10.4102/ } \\
\text { aveh.v80i1.581 }\end{array}$} \\
\hline \multicolumn{2}{|c|}{$\begin{array}{l}\text { Copyright: } \\
\text { (c) 2021. The Author } \\
\text { Licensee: AOSIS. This } \\
\text { is licensed under the } \\
\text { Creative Commons } \\
\text { Attribution License. }\end{array}$} \\
\hline \multicolumn{2}{|l|}{ Read online: } \\
\hline 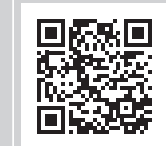 & $\begin{array}{l}\text { Scan this QR } \\
\text { code with your } \\
\text { smart phone or } \\
\text { mobile device } \\
\text { to read online. }\end{array}$ \\
\hline
\end{tabular}

Background: Evidence-based contextual diabetic retinopathy (DR) related health promotion tools are essential in improving patient compliance and reducing the condition-related burden within the community.

Aim: This study compares DR related knowledge impact amongst the population following the traditional print based health education over the developed visual simulations.

Setting: This prospective cross-sectional study was conducted within a province in Oman over the duration of one year.

Methods: One hundred and thirty-six (50.6\%) participants were provided with print-based and $133(49.4 \%)$ with visual-simulation-based DR related health promotional intervention. A questionnaire and model responses were designed and validated to assess the knowledge of the participants about DR.

Results: The improvement in DR related knowledge scores was slightly higher in the printbased version $(17.88 \%)$ compared to the visual-simulation-based $(15.77 \%)$ health education. However, the Mann Whitney $U$ test indicated a statistically insignificant $(U=8446.5, p=0.348)$ difference in change in the knowledge scores between these groups following the provision of DR related health education either with the print-based or visual-simulation-based version.

Conclusion: Print-based, as well as visual-simulation-based health educational interventions are effective in improving DR related knowledge. Although there is not enough evidence to support the visual-simulation method over the print-based DR health education, observing the similar positive impact upon the DR knowledge level with the latter method, this study suggests the use of these contextual visual simulations as an alternative strategy of DR health education. There is a need to develop evaluation strategies for the health promotional tools. The evidence-based health promotional tools are recommended to be integrated within the eye health system.

Keywords: health promotion; diabetes mellitus; diabetic retinopathy; primary care; optometry; ophthalmology; vision science.

\section{Background}

The prevalence of diabetes mellitus (DM) is on the rise worldwide as well as in the Sultanate of Oman. ${ }^{1}$ A previous study in the Sultanate of Oman has stated that approximately $10 \%$ of the native population is suffering from DM and highlighted the need for developing the DM related health promotional resources. ${ }^{2}$ Diabetic retinopathy (DR) is an associated 'microvascular complication' of DM that can lead to irreversible visual impairment. A recent study within the Sultanate of Oman observed DR prevalence of $31 \%$. $^{3}$

The Healthcare system in the Sultanate of Oman maintains a 'National Diabetes Register'. It also follows the guidelines provided by the World Health Organization and recommends yearly ophthalmic check-up for individuals having DM. ${ }^{1}$ The Sultanate of Oman has state-of-the-art primary healthcare facilities as well as the 'National Diabetic Control Programme'. The preventive as well as treatment approaches are provided to the community under the governmental support. The National Eye Health Care programme has recommended screening initiatives at the secondary centres following the preventive measures. ${ }^{1}$ The committee also recommends the integration of 
the involved stakeholders in improving the efficiency of the eye healthcare system. The committee also recommends adding the rehabilitative services for the conditions related to the visually impaired community. ${ }^{1}$

Individuals' condition-related knowledge can be pivotal in their disease management. It forms the basis of various health promotional constructs. ${ }^{4}$ For instance, the selfdetermination theory focuses on individual ability and rights in the decision-making process. Self-determination is observed to have a higher impact whilst managing the disease-related determinants of the affected individuals. It positively enhances the behaviour as well as the attitude of the affected individual to improve his compliance towards the disease management. It helps by providing autonomy, competency and his own responsibilities to follow the desired health behaviour. ${ }^{5}$

The community can also be made aware of DR related health promotional sources available for the visually impaired population. ${ }^{6}$ Another study conducted in an urban province of the Sultanate of Oman identified that only $24 \%$ of the schools' students population had adequate knowledge about diabetes. Hence, the authors of the later study recommended implementing condition-related health education programmes within the population. ${ }^{7}$ Such health promotional activities can enhance DR related knowledge within the at-risk population.

Higher disease-related knowledge is well known to link with improved patient compliance towards their disease management. ${ }^{8,9} \quad$ Patient-noncompliance towards the management of DR could be because of their personal barriers, or the current lacunae in the eye healthcare system. ${ }^{6}$ Patient-related factors are awareness, beliefs, cost, distance, efforts, and time. ${ }^{9}$ Whereas the service-related factors are stated as poor counselling, longer waiting time, inadequate facilities, or referral mechanisms. Amongst these, counselling can be related to health education. Reasons for improper counselling could be multifactorial such as insufficient chair time, a negative attitude of the health professionals towards educating the community, or the availability of health promotional resources and its effectiveness. ${ }^{10}$ Using a costeffective, flexible, technology-based platform could be the support strategies ${ }^{10}$ to follow parallel to the traditional methods of counselling.

Innovations in eye health service deliveries are crucial in increasing patient compliance for the required preventive measures. ${ }^{6}$ Similar innovations in health promotion activities can positively impact the effectiveness of the provided managerial approaches to prevent the burden of DR related visual impairment. ${ }^{10}$ For instance, the mobile health intervention used in one of the studies provided the awareness about diabetic-related ophthalmic care by incorporating healthcare reminders using text messaging service. Such tools support the individuals having diabetes, or the communities at risk in prevention as well as further managements in improving their quality of life. ${ }^{5}$ An intervention design based on the systematic approach followed by applying the different theories based on the consensus of the various stakeholders is more likely to be successful in improving the health outcomes within the affected community. ${ }^{11}$

However, there are limited studies evaluating the impact of the various DR health educational resources on enhancing the knowledge level amongst the community. We developed a contextual based DR related health education tool. ${ }^{4}$ It can be circulated to the community through social media platforms without any additional cost or time for practitioners or patients. ${ }^{4}$ The tool has the components of knowledge about the condition itself, prevention, treatments and rehabilitative options. The tool can support reducing the counselling-related burden amongst eye care professionals. ${ }^{4}$ Prior studies have been conducted to evaluate the impact of DR educational programmes amongst the diabetic population. ${ }^{12}$ However, the effectiveness of various tools have not been directly compared before their implementation within the general population. ${ }^{4}$

In summary, because of the increasing prevalence of DM in the Sultanate of Oman, there is a need to enhance the DR related knowledge levels amongst the community. An evidence-based contextual DR related health promotion tool is designed to achieve this goal. However, it is necessary to evaluate its impact on the traditional approaches of DR health education. Hence, this study compares DR knowledge impact amongst the population following the traditional print-based health education over the developed visual simulations. The study findings could be useful in suggesting the best possible educational platforms providing a faster and better understanding of the condition-related care. This can further reduce the burden of DR within the community.

\section{Objectives}

- To compare the change in DR related knowledge scores following the traditional print-based health education.

- To compare the change in DR related knowledge scores following the contextual and evidence-based health promotion design.

- To compare the DR related knowledge impact following the traditional print-based health education over visual simulations.

\section{Methods}

We used the online software 'Open Source Epidemiologic Statistics for Public Health Version 3.01 (Updated 06 April 2013)' provided by the Centre for Disease Control and Prevention in the United States of America to calculate the sample size. The national population of Al Batinah (south and north) is $435618 .^{13}$ A national diabetic prevalence of $15 \%$ was hypothesised within the diabetic population with a confidence interval of $95 \%$. Considering the non-respondent's rate of $10 \%$ 
the study needed to contact a total of 250 participants (125 in each group) of which a total of 89 responses were calculated to be sufficient to generalise the results. We used a convenient sampling method to include study participants and received 269 responses out of 300 potential participants. The study included native residents of $\mathrm{Al}$ Batinah in the Sultanate of Oman and was conducted from February 2019 to February 2020. The nationality, DM related personal or family history and the demographic information of the participants was selfdeclared. All the willing participants aged 19 and above were eligible to participate in the study, with the exclusion of minors and vulnerable people. The age range of the volunteered participants was 19 years to 70 years. Participants with different socioeconomic backgrounds, genders, medical, or non-medical professions were included in the study. However, participants residing in the other parts of the Sultanate of Oman and or working in the field related to eye care including ophthalmologists and optometrists were excluded from the study. Knowledge of diabetic retinopathy amongst the eligible and volunteering participants was initially assessed using a self-designed questionnaire (Appendix 1). The participants' responses were collected two times, pre- and post-health educational interventions, using the same questionnaire. The questionnaire was not exposed to the study participants. A native field investigator with an optometric background and proficiency in the Arabic language was trained to collect the responses using the selfdesigned questionnaire. The details of the design and validation of the DR knowledge questionnaire are mentioned below. The collected responses were then compared with the approved model answers whilst grading the DR knowledge of the participants. The participants were then provided with either print-based or visual-simulation-based DR health education. Both the methods of educational intervention were implemented during individual face-to-face interactions. The choice of the chosen method was done randomly through a lottery system. Two chits were prepared mentioning only one type of health education technique in each chit. The participant blindly chose only one chit having the name of the DR health education technique to be followed by them. The DR knowledge was reassessed immediately post-intervention to evaluate the impact of the provided intervention. Post intervention, the DR knowledge-related responses were recollected, using the same questionnaire used before the health educational intervention to evaluate the knowledge outcome of the provided intervention.

\section{Knowledge assessment questionnaire}

The questionnaire and model responses were designed to assess the knowledge of the participants about DR, and it included a total of 32 items. The knowledge component focused on the questions related to knowledge about the condition itself, community prevalence, risk factors and the importance of ocular examination as well as treatment and rehabilitative options available to manage the condition. The survey was first prepared in the English language and then translated to the Arabic language. The validity of the translation was assessed by the language expert before its use in the study. The survey was conducted in the Arabic language.

The questionnaire and model responses related items were validated using a content validity approach. Validators' responses were obtained by responses of ' +1 ' indicating positive response towards the item to be included in the questionnaire and ' -1 ' indicating the deletion or modifications of the corresponding item from the questionnaire. The justification section was also provided to the validators to provide their comments on the reason for the deletion or requiring modifications. An agreement of $80 \%$ ensured the validity of the included items.

The Pearson correlation test was used to assess the validity of the questionnaire. To ensure the validity of the study questionnaire using Pearson correlation test, each participant responded to the same questionnaire after the interval of 15 days. These participants were not exposed to the health intervention during the validation of this study tool. Cronbach's Alpha test was used to ensure the internal validity of the questionnaire.

\section{Visual simulation}

We used a contextual and evidence-based DR healthpromotion visual simulation developed in our previous study. ${ }^{4}$ It was circulated free of cost and without discrimination within the Omani community. ${ }^{4}$

The duration of the animated video is $6 \min 51 \mathrm{~s}$, with the shortest and simplest visual cues to remember the important key points and to improve the individual's condition-related compliance. This audio-visual format is compatible with all the web browsers and can be viewed on personal computers, mobile phones as well as tablets supporting a browser. It consists of the information on associated risk factors, the importance of routine ocular examinations, preventive measures, available medical or surgical treatments and rehabilitative options whilst managing the condition of DR. The audio within the health promotional tool is provided in Arabic language with English subtitles. ${ }^{4}$

\section{Printed version}

The transcript used in the visual simulation format in the Arabic language was printed. The printed version incorporates all the colour images of the maps and conditionrelated photographs that were used in the visual simulation format.

\section{Data storage and analysis}

The data on knowledge scores before and after providing health education through both the methods in two groups were initially collected using hard copies. It was then transferred to Microsoft Excel 2013 for further analysis. The Statistical Package for Social Sciences (SPSS) version 21 
developed by International Business Machines (IBM) Corporation, United States was used for data analysis. The Shapiro Wilk test was used to check the normality of knowledge scores before and after the provision of the two DR related health educational methods. Effectiveness of the applied educational methods in improving the participants' diabetes-related knowledge was assessed using the Wilcoxon Signed Rank test for print-based group. The Mann Whitney $U$-test compared the percentage change scores between print and visual simulation group (for non-normal distribution). Paired $T$-test and independent $T$-test were used (for normal distributions) in the visual-simulationbased group.

\section{Results}

\section{The demographic profile of the study participants}

Out of a total of 269 participants, $72.5 \%$ were females and $27.5 \%$ were males. About 136 (50.56\%) study participants were provided with the print-based and 133 (49.4\%) with the visual-simulation-based DR related health promotional intervention. Most of the participants (98.6\%) had an educational level of secondary school level or higher (Table 1).

TABLE 1: The demographic profile of the study participants.

\begin{tabular}{|c|c|c|c|}
\hline \multirow[t]{2}{*}{ Variables } & \multicolumn{2}{|c|}{$\begin{array}{l}\text { Type of DR related } \\
\text { health education }\end{array}$} & \multirow[t]{2}{*}{$\begin{array}{l}\text { Total } \\
(\%)\end{array}$} \\
\hline & $\begin{array}{c}\text { Print- based } \\
(\%)\end{array}$ & $\begin{array}{l}\text { Visual-simulation- } \\
\text { based }(\%)\end{array}$ & \\
\hline \multicolumn{4}{|l|}{ Gender } \\
\hline Male & 19.3 & 8.2 & 27.5 \\
\hline Female & 31.2 & 41.3 & 72.5 \\
\hline \multicolumn{4}{|l|}{ Education level } \\
\hline Illiterate & 0.4 & 0.4 & 0.7 \\
\hline Primary & 0.4 & 0.4 & 0.7 \\
\hline Tertiary & 4.5 & 0.4 & 4.8 \\
\hline Graduate & 38.7 & 42.4 & 81.0 \\
\hline Postgraduate & 3.3 & 4.5 & 7.8 \\
\hline Graduate/Postgraduate & 3.3 & 1.5 & 4.8 \\
\hline \multicolumn{4}{|l|}{ Education-related medical field } \\
\hline Related to the medical field & 13.0 & 25.7 & 38.7 \\
\hline Not related to the medical field & 37.5 & 23.8 & 61.3 \\
\hline \multicolumn{4}{|l|}{ Occupation related to medical } \\
\hline Related to the medical field & 11.5 & 24.9 & 36.4 \\
\hline Not related to the medical field & 39 & 24.5 & 63.3 \\
\hline \multicolumn{4}{|l|}{ Father's education level } \\
\hline University level & 9.3 & 15.2 & 24.5 \\
\hline High school level & 19.7 & 20.4 & 40.1 \\
\hline Elementary level & 10.8 & 10.4 & 21.2 \\
\hline Illiterate & 10.8 & 3.3 & 14.1 \\
\hline \multicolumn{4}{|l|}{ Mother's education level } \\
\hline University level & 6.7 & 9.3 & 16.0 \\
\hline High school level & 14.5 & 19.3 & 33.8 \\
\hline Elementary level & 15.2 & 11.9 & 27.1 \\
\hline Illiterate & 14.1 & 8.9 & 23.0 \\
\hline \multicolumn{4}{|l|}{ Parent-related medical field } \\
\hline Related to the medical field & 4.8 & 5.6 & 10.4 \\
\hline Not related to the medical field & 45.7 & 43.9 & 89.6 \\
\hline
\end{tabular}

DR, diabetic retinopathy.

\section{Diabetic profile of study participants}

Of the total participants, $2.2 \%$ had personal as well as a family history of DM. Participant's responses on the prevalence of DM and its type were self-declared. Amongst this diabetic population Type $2 \mathrm{DM}(1.1 \%)$ was more common than Type $1 \mathrm{DM}(0.7 \%)$ and few participants $(0.4 \%)$ did not know their type of DM (Table 2).

\section{Change in diabetic retinopathy related knowledge score following the provision of print-based health education}

The mean age of the study participants provided with printbased DR health education was 23.46 years \pm 7.81 (range: 19-70 years). The Wilcoxon signed ranked test indicated, a statistically significant $(p<0.01)$, positive change in the percentage knowledge score $(17.9 \%)$ post-intervention (Table 3).

\section{Change in diabetic retinopathy related knowledge score following the provision of visual-simulation-based health education}

The mean age of the total 133 participants that were provided with visual-simulation-based DR health education was $22.93 \pm 7.13$ (range: $19-53$ ). A paired $t$-test indicated a statistically significant $(p<0.01)$ positive change in knowledge score $(15.77 \%)$ amongst this group, post visual-simulation-based health educational intervention (Table 4).

\section{Comparing the knowledge score impact following the provision of the print-based version over the visual-simulation-based diabetic retinopathy education}

The improvement in DR related knowledge scores was slightly higher in the print-based version (17.9\%) compared to the visual-simulation-based (15.8\%) health education (Figure 1). However, the Mann Whitney U-test indicated that there was a statistically insignificant $(U=8446.5, p=0.348)$ difference in change in the knowledge scores between these

TABLE 2: Diabetic profile of study participants.

\begin{tabular}{lccc}
\hline Variable & \multicolumn{2}{c}{$\begin{array}{c}\text { Type of DR related } \\
\text { health education }\end{array}$} & \multirow{2}{*}{$\begin{array}{c}\text { Total } \\
\text { (\%) }\end{array}$} \\
\cline { 2 - 3 } & $\begin{array}{c}\text { Printed- } \\
\text { based (\%) }\end{array}$ & $\begin{array}{c}\text { Visual-simulation- } \\
\text { based (\%) }\end{array}$ & \\
\hline Do you have diabetes mellitus? & 1.5 & 0.7 & 2.2 \\
Yes & 47.2 & 45.4 & 92.6 \\
No & 1.9 & 3.3 & 5.2 \\
I do not know & & & \\
Participant's type of diabetes mellitus & 49.1 & 48.7 & 97.8 \\
Not applicable & 0.4 & 0.4 & 0.7 \\
Type 1 & 0.7 & 0.4 & 1.1 \\
Type 2 & 0.4 & 0.0 & 0.4 \\
I do not know the type of diabetes mellitus & & & \\
Family history of diabetes & 49.1 & 48.7 & 97.8 \\
No responses & 1.5 & 0.7 & 2.2 \\
\hline Yes & & &
\end{tabular}

DR, diabetic retinopathy. 
TABLE 3: Change in diabetic retinopathy related knowledge score following the provision of print-based health education

\begin{tabular}{|c|c|c|c|c|c|}
\hline Knowledge scores among group receiving print-based health education & Changes (\%) & Minima (\%) & Maxima (\%) & Means (\%) & SD (\%) \\
\hline Knowledge score before the provision of print-based DR health education & 53.13 & 0.00 & 53.13 & 19.42 & 13.98 \\
\hline Knowledge score after the provision of print-based DR health education & 71.88 & 6.25 & 78.13 & 37.29 & 14.15 \\
\hline Percentage change in knowledge score after the provision of print-based DR health education & 65.63 & -9.38 & 56.25 & 17.88 & 13.77 \\
\hline
\end{tabular}

$\mathrm{DR}$, diabetic retinopathy; SD, standard deviation.

TABLE 4: Change in diabetic retinopathy related knowledge score following the provision of visual-simulation-based health education.

\begin{tabular}{|c|c|c|c|c|c|}
\hline Knowledge scores among group receiving visual-simulation-based health education & Changes (\%) & Minima (\%) & Maxima (\%) & Means (\%) & SD (\%) \\
\hline Knowledge score before the provision of visual-simulation-based DR health education & 62.50 & 0.00 & 62.50 & 24.08 & 16.26 \\
\hline Knowledge score after the provision of visual-simulation-based DR health education & 75.00 & 0.00 & 75.00 & 39.85 & 12.81 \\
\hline $\begin{array}{l}\text { Percentage change in knowledge score after the provision of visual-simulation-based DR health } \\
\text { education }\end{array}$ & 68.75 & -25.00 & 43.75 & 15.77 & 13.79 \\
\hline
\end{tabular}

$\mathrm{DR}$, diabetic retinopathy; SD, standard deviation.

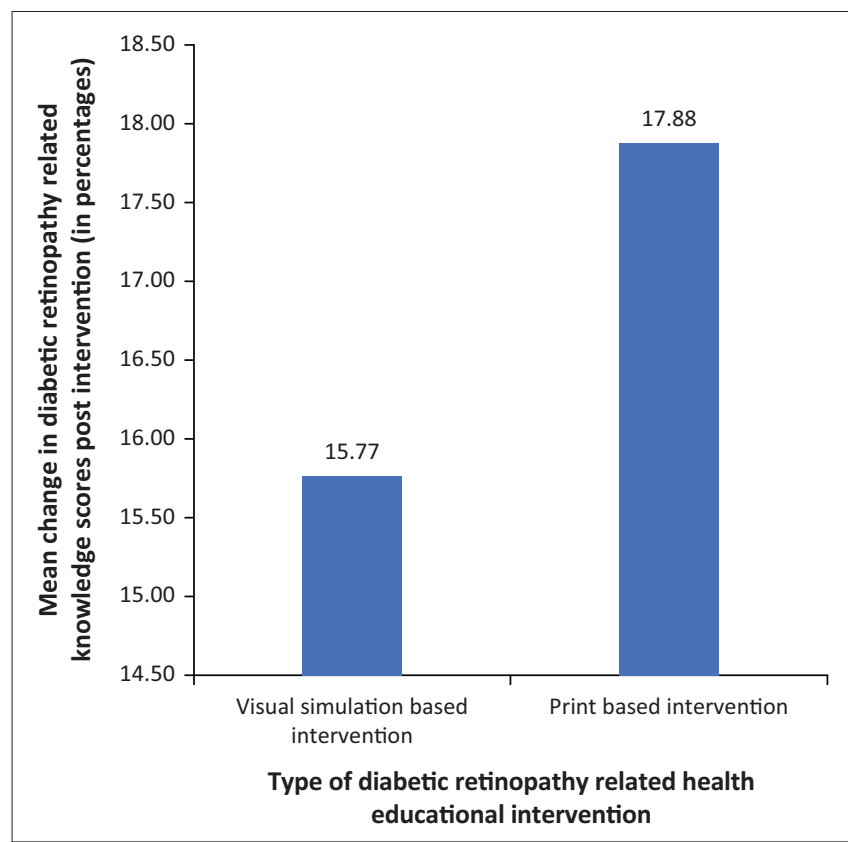

FIGURE 1: Comparing the mean change in diabetic retinopathy related knowledge scores post health educational intervention of visual-simulationbased over print-based approach.

groups following the provision of DR related health education either with the print-based or the visual-simulation-based versions.

\section{Discussion}

This study evaluated knowledge impact of visual-simulationbased DR health education over the traditional print-based method amongst the Omani community residing amongst $\mathrm{Al}$ Batinah. Although we gave equal preference to both genders, this study has lower (27.5\%) participation of males. This could be because of higher health consciousness amongst the females. We found that both types of DR health education were effective in improving the community's conditionrelated knowledge. These study results are similar to a hospital-based study in Egypt that observed the increased DR knowledge. ${ }^{12}$ Also, these positive impacts on knowledge level are similar to the other study that used a 'mobile health' intervention that was designed based on the selfdetermination theoretical constructs of the health promotion. ${ }^{5}$ The mobile health also observed a positive change in the health behaviour of the community post intervention towards their disease prevention as well as the treatments.

This study did not find any statistically significant change in knowledge scores through the visual-simulation-based method $(15.8 \%)$ over the print-based method (17.9\%) of health education ( $U=8446.5, p=0.348)$. Moreover, visualsimulation-based methods can be advantageous over printbased methods as a result of its cost-effectiveness and flexibility by way of its availability over the internet as per the need and convenience of the community. This could also reduce the counseling burden for the busy ophthalmologist.

Previous studies evaluating DR related knowledge amongst communities have observed marked variations in knowledge levels in different study populations. A study that was conducted in the capital of the Sultanate of Oman in 2008 indicated the awareness of visual impairment because of DR amongst the majority (70\%) of the study population. ${ }^{14,15}$ However, another study done within the same region indicated only $24 \%$ of the study population had adequate knowledge about the condition. ${ }^{7}$ As the latter study was conducted amongst the student population, the results were not directly comparable. However, there are clear indications of the need for conducting condition-related health educational activities to improve their knowledge levels.

The link between improved health behaviour with higher condition-related knowledge levels is well established. ${ }^{9,12,16}$ Further studies on recent DR health educational advancements through mobile health ${ }^{5}$ or a study based on telemedicine platforms for patient screening, accompanied by health education have also observed a similar pattern. ${ }^{17}$ However, it is important to evaluate the impact of different health-education methods suitable to the community to yield the optimum programme outcome. Hence, this study helps in filling the evidence gap regarding the different educational interventions focusing on DR.

A health promotional tool based on the theoretical constructs, integrating the involved stakeholders ${ }^{11}$ could be the key to enhance the output of the overall healthcare system and patient satisfaction. The findings support the use of health promotional tools as being those that can be circulated online 
and cost effective; tools that are convenient for use by the involved stakeholders, whilst reducing the counselling burden of eye health professionals. Such tools can also be integrated within the healthcare system, ${ }^{1}$ to promote the health education within the concerned community. The findings also support the future modifications or designing of the evidence-based strategies of the current health promotional tools.

\section{Limitations}

Implementation of DR health intervention programmes based on the evidence-based health promotional framework can help raise awareness about the condition. This study result cannot be generalised because of the convenience sampling technique used whilst recruiting the study participants. Also, we assessed the impact on the knowledge score immediately post-intervention. The suitability of the intervention provided was not assessed on the parameter supporting memory-retention of the involved participants, or the required change in their health behaviour. Further comparisons can be done using other approaches such as focus groups or personal counselling sessions for providing DR related health information. Inputs can also be obtained from the involved stakeholders to overcome the current lacunae whilst preparing the future DR health promotional resources. This study provides a baseline for the impact of the contextual health information within the at-risk, as well as the non-risk community. The study findings validate the health promotion initiatives. However, it also highlights the need for further research comparing the different DR health promotional platforms and strategies to improve the compliance of the at-risk community.

\section{Conclusion}

Print based, as well as visual-simulation-based health educational interventions are effective in improving DR related knowledge. Although there is not enough evidence to support the visual-simulation-based method over the printbased DR health education, observing the similar positive impact upon the DR knowledge level with the latter method, this study suggests the use of these contextual visual simulations as an alternative strategy of DR health education. There is a need to develop evaluation strategies for the health promotional tools. The evidence-based health promotional tools are recommended to be integrated within the eye health system.

\section{Acknowledgements Competing interests}

The authors have declared that no competing interests exist.

\section{Authors' contributions}

G.O.V. and S.M.R.D.A.S. contributed equally to the design and implementation of the research, to the analysis of the results and to the writing of the manuscript.

\section{Ethical considerations}

The prospective cross-sectional study obtained approval by the Research and Ethics committee of the College of Health Sciences of the University in Buraimi, the Sultanate of Oman. It followed the guidelines mentioned in the Declaration of Helsinki. Participants provided with a brief study background and advantages of this study before their enrolment into the study. Prior consent was taken from all the eligible participants willing to participate in this study.

\section{Funding information}

This research received no specific grant from any funding agency in the public, commercial or not-for-profit sectors.

\section{Data availability}

Data sharing is not applicable to this article.

\section{Disclaimer}

The views and opinions expressed in this article are those of the authors and do not necessarily reflect the official policy or position of any affiliated agency of the authors.

\section{References}

1. Khandekar RB, Al-Lawati JA. Epidemiology of diabetic retinopathy in Oman: Two decades of research. Oman J Ophthalmol. 2015;8(1):1-2. https://doi.org/ 10.4103/0974-620X.149853

2. Al Bimani ZS, Khan SA, David P. Evaluation of T2DM related knowledge and practices of Omani patients. Saudi Pharm J SPJ. 2015 Jan;23(1):22-27. https://doi. org/10.1016/j.jsps.2013.12.006

3. Agroiya P, Alrawahi AH, Pambinezhuth F, Busaidi NBA. Diabetic retinopathy among Omanis: Prevalence and clinical profile. Oman J Ophthalmol. 2020 Jan 5;13(2):76. https://doi.org/10.4103/ojo.OJO_225_2019

4. Vankudre GS. Diabetic retinopathy related health educational intervention A contextual and evaluation based design. TEXILA Int J PUBLIC Health. 2016;7(2): 1-7. https://doi.org/10.21522/TIJPH.2013.07.02.Art001

5. Umaefulam V, Premkumar K. Impact of mobile health in diabetic retinopathy awareness and eye care behavior among Indigenous women. mHealth. 2020;6:14. https://doi.org/10.21037/mhealth.2019.12.01

6. Lewis K. Improving patient compliance with diabetic retinopathy screening and treatment. Community Eye Health. 2015;28(92):68-69.

7. Al-Mahrooqi B, Al-Hadhrami R, Al-Amri A, et al. Self-reported knowledge of diabetes among high school students in Al-Amerat and Quriyat, Muscat Governate, Oman. Sultan Qaboos Univ Med J. 2013 Aug;13(3):392-398. https:// doi.org/10.12816/0003261

8. Venugopal D, Lal B, Fernandes S, Gavde D. Awareness and knowledge of diabetic retinopathy and associated factors in Goa: A hospital-based cross-sectional study. Indian J Ophthalmol. 2020 Feb;68(2):383-390. https://doi.org/10.4103/ijo. IJO_1218_19

9. Alwazae $\mathrm{M}, \mathrm{Al}$ Adel $\mathrm{F}$, Alhumud $\mathrm{A}$, Almutairi A, Alhumidan A, Elmorshedy $\mathrm{H}$. Barriers for adherence to diabetic retinopathy screening among Saudi adults. Cureus. 2019;11(12):e6454. https://doi.org/10.7759/cureus.6454

10. Beaser RS, Turell WA, Howson A. Strategies to improve prevention and management in diabetic retinopathy: Qualitative insights from a mixed-methods study. Diabetes Spectr Publ Am Diabetes Assoc. 2018 Feb;31(1):65-74. https:// doi.org/10.2337/ds16-0043

11. Riordan F, Racine E, Phillip ET, et al. Development of an intervention to facilitate implementation and uptake of diabetic retinopathy screening. Implement Sci. 2020 May 19;15(1):34. https://doi.org/10.1186/s13012-020-00982-4

12. Khalaf FR, Fahmy HM, Ibrahim AK, et al. Does a diabetic retinopathy educational program raise awareness among elderly diabetic patients? Diabetes Metab Syndr Obes Targets Ther. 2019Sep 20;12:1867-1875. https://doi.org/10.21522/10.2147/ DMSO.S208072

13. Ministry of Foreign Affairs. Governorates of Sultanate of Oman وزارة ال خارج ية ال عمان ية 2019 May 30]. Available from: https://www.mofa.gov.om?p=1063\&lang=en 
14. Khandekar R, Al-Harby S. Knowledge and attitude for eye diseases and satisfaction for services among urban citizens of Oman: A pilot study. Oman J Ophthalmol. $2008 \operatorname{Jan}$ 9;1(1):13. https://doi.org/10.4103/0974-620X.43315 15. Al-Mujaini AS. Knowledge, attitudes, and practices related to common eye
diseases among the Omani population: How far have we come? Oman Med J. 2020 Jan 27;35(1):e96-e96. https://doi.org/10.5001/omj.2020.14
16. Zandiyeh Z, Hedayati B, Zare E. Effect of public health nurses' educational intervention on self-care of the patients with type 2 diabetes. I Educ Health Promot. 2015;4:88. https://doi.org/10.4103/2277-9531.171802

17. Moinul P, Barbosa J, Qian J, et al. Does patient education improve compliance to routine diabetic retinopathy screening? J Telemed Telecare. 2020 Apr 1;26(3): 161-173. https://doi.org/10.1177/1357633X18804749 


\section{APPENDIX 1: Questionnaire-study tool}

Demographic information of the participant:

\begin{tabular}{ll}
\hline Sr. No. & \\
\hline 1 & Age: \\
2 & Gender: \\
3 & Personal educational level: \\
4 & Educational background: \\
5 & 1. Medical related 2. Non-medical \\
6 & Address/Province of residence: \\
7 & Occupation: \\
8 & Occupational background: 1. medical related 2. Non-medical \\
9 & Father's Educational level: \\
10 & Mother's Educational level: \\
\hline
\end{tabular}

Sr. No., serial number.

Diabetes related personal information:

Personal history of diabetes

Type of diabetes

Duration of diabetes

Family history of diabetes

\section{Related to diabetes and the eye}

Knowledge-related questions:

Knowledge-related questions guidelines:

1

About diabetes

\section{Knowledge related to ocular effects of diabetes}

Does DM affect bodily organs?

Which body parts are affected by diabetes?

What problems can patients with diabetes have in the eye?

How does it affect the back part of the eye?

Diabetes-related risk factors for the changes in the back part of the eye? Which type of diabetes can affect the eye?

Is the duration of diabetes related to level of eye health complications?

Can diabetes lead to blindness?

Can we completely regain the lost vision because of diabetes?

What are the ocular symptoms because of the condition?
Knowledge related to preventive measures of diabetes

$\begin{array}{ll}12 & \text { Can you prevent diabetes-related ocular effects? } \\ 13 & \text { If yes, how can we prevent diabetes-related ocular effects? } \\ 14 & \text { How frequent should be the eye check-up visit? }\end{array}$

Knowledge related to diagnostic tests used for examining ocular effects of diabetes

15

Name the diagnostic tests used for examining ocular effects of diabetes?

Knowledge related to treatment options for ocular effects of diabetes

16 Treatment options available for diabetic retinopathy?

Knowledge related to rehabilitative services

17 If the vision is affected, apart from spectacles, medicines and managed diet, are there any other modes of management?

Source of information for diabetic retinopathy:

18

Source of Information 